\title{
The inclusion of a business management module within the master of pharmacy degree: a route to asset enrichment?
}

\author{
Michael J. DAVIES, Hannah FLEMING, Richard JONES, Kate MENZIE,
} Christine SMALLWOOD, Sebastian SURENDAR.

Received (first version): 31-Jan-2013 Accepted: 22-May-2013

\begin{abstract}
${ }^{*}$
Background: Over the past decade the profession of pharmacy has steadily evolved. The New Pharmacy Contract exposed pharmacists to a fundamental change in traditional pharmacy business models.

Objective: This study will consider whether community pharmacists, pharmacy undergraduates and academic staff within the United Kingdom believe it would be beneficial to incorporate a business management module within the Master of Pharmacy (MPharm) undergraduate degree along with potential mechanisms of delivery.

Methods: Further to ethical approval, the questionnaire was distributed to UK registered pharmacists $(n=600)$, MPharm undergraduates $(n=441)$ and academic staff at Liverpool John Moores University $(n=44)$. The questions were formatted as multiple choice questions, Likert scales or the open answer type. On questionnaire completion and return, data were analysed using simple frequencies, cross tabulations and nonparametric techniques in the SPSS (v18).

Results: The majority of pharmacists (84.9\%) confirmed that business skills affect their everyday responsibilities to a considerable extent. A high proportion of undergraduate students $(92.8 \%)$ believed that business management skills will impact on their future role. In total, $64.3 \%$ of this cohort declared that if a module were introduced they would study it. The majority of staff (79\%) agreed that business skills are gaining increased importance within the field of pharmacy.

Conclusions: Data suggest that business skills are of relevance to the practice of pharmacy.
\end{abstract}

Appropriate staff to deliver the taught material would

*Michael J. DAVIES. PhD, MPharm, MRPharmS, FHEA. The School of Pharmacy and Biomolecular Sciences, Liverpool John Moores University (LJMU), Liverpool, (United Kingdom).

Hannah FLEMING. The School of Pharmacy and Biomolecular Sciences, Liverpool John Moores University (LJMU), Liverpool, (United Kingdom).

Richard JONES. The School of Pharmacy and Biomolecular Sciences, Liverpool John Moores University (LJMU), Liverpool, (United Kingdom).

Kate MENZIE. The School of Pharmacy and Biomolecular Sciences, Liverpool John Moores University (LJMU), Liverpool, (United Kingdom).

Christine SMALLWOOD. The School of Pharmacy and Biomolecular Sciences, Liverpool John Moores University (LJMU), Liverpool, (United Kingdom).

Sebastian SURENDAR. The School of Pharmacy and Biomolecular Sciences, Liverpool John Moores University (LJMU), Liverpool, (United Kingdom). include business owners / lecturers and teaching practitioners covering topics including management, leadership, interpersonal skills and regulation. We suggest the inclusion of a business module with the MPharm degree would be of great value in preparing individuals for practice within a modern day healthcare setting.

Keywords: Education, Pharmacy; Students, Pharmacy; Professional Competence; Pharmacy Administration; United Kingdom

\section{INCLUSIÓN DE UN MÓDULO DE GESTIÓN DE EMPRESA EN EL GRADO DE MASTER EN FARMACIA: UN CAMINO HACIA LA MEJORA?}

\section{RESUMEN}

Antecedentes: Durante la década pasada, la profesión de farmacia ha evolucionado firmemente. El New Pharmacy Contract expuso a los farmacéuticos a un cambio en los modelos tradicionales de negocio.

Objetivo: Este estudio considerará si los farmacéuticos, estudiantes de farmacia y académicos en Reino Unido se beneficiarían incorporando un módulo de gestión de empresa en el grado de Master en Farmacia (MPharm) así como los potenciales mecanismos de enseñanza. Métodos: Después de la aprobación de ética, se distribuyó el cuestionario e farmacéuticos en ejercicio en Reino Unido ( $n=600$ ), estudiantes del MPharm $(n=441)$ y personal académico de la Liverpool John Moores University $(n=44)$. Las preguntas tenían formato de preguntas de elección múltiple, escalas de Likert o preguntas abiertas. Cuando se cumplimentaban y retornaban los cuestionarios, se analizaron los datos usando frecuencias simples, tablas cruzadas y técnicas noparamétricas con el SPSS (v18).

Resultados: La mayoría de los farmacéuticos $(84,9 \%)$ confirmó que las habilidades empresariales afectan sus responsabilidades diarias en grado considerable. Una proporción elevada de estudiantes (92,8\%) creía que las habilidades en gestión empresarial tendrían impacto en su papel futuro. En total, el 64,3\% de esta cohorte declaró que si se introdujese un módulo, lo estudiarían. La mayoría del personal académico (79\%) concordó que las habilidades empresariales están ganando importancia en el campo de la farmacia.

Conclusiones: Los datos sugieren que las habilidades empresariales son de relevancia en la práctica de la farmacia. El personal adecuado para 
proporcionar el material docente debería incluir propietarios, y profesores de prácticas que cubran los temas como gestión, liderazgo, habilidades interpersonales y legislación. Sugerimos que la inclusión de un módulo de empresa en el grado de MPharm sería de gran valor en la preparación de los individuos para el ejercicio en los establecimientos sanitarios modernos.

Palabras clave: Educación en Farmacia; Estudiantes de Farmacia; Competencia Profesional; Administración Farmacéutica; Reino Unido

\section{INTRODUCTION}

Over the course of the last decade the profession of pharmacy within developed countries (i.e. the United Kingdom (UK) and United States of America (USA)) has evolved from largely dispensing medicinal products to being keenly focussed on the delivery of pharmaceutical care. ${ }^{1,2}$ Such progression has led to a notable shift in clinical service provision to the pharmacy sector. ${ }^{3}$ With respect to the UK, the boundaries between healthcare professionals are rapidly merging thus allowing for more clinical, less routine activities to be incorporated into the daily running of community pharmacy premises. ${ }^{4}$ A key catalyst for this change was the implementation of the Alternative Provider Medical Services directions in 2004, which intended to improve public access to healthcare via outsourcing medical services from general practitioners to additional providers. $^{5}$ In response, the 2005 'New Pharmacy Contract' was developed and incorporates a range of clinical services for pharmacists to perform ${ }^{3}$; including for example essential (i.e. prescription dispensing), advanced (i.e. Medicines Use Reviews (MURs) \& New Medicines Service (NMS)) and enhanced services (i.e. emergency hormonal contraception). ${ }^{6}$ The implementation of the new pharmacy contract led to a significant shift in the traditional business models of pharmacy, in that the contactor is not only remunerated for basic responsibilities (i.e. prescription dispensing) but also for a more progressive range of services offered to patients. ${ }^{7,8}$

In terms of prescription dispensing, reimbursement prices are being continually driven down, hence decreasing profit margins for the contractor. ${ }^{9}$ As part of the 2011 / 2012 financial settlement by the UK government, changes were made to the Drug Tariff from April 2011, including a GBP20 million reduction in fees and allowances for community pharmacies and a GBP90 million reduction in certain medicinal categories. ${ }^{10}$ The changes to government remuneration have meant that pharmacies must respond appropriately and deliver a range of progressive profit driven services in order to draw revenue and hence survive.

Thus, we suggest that the profession of pharmacy and business management are intricately linked. The term 'pharmacy business management' includes various elements that must fuse together effortlessly to allow for the effective operation of a pharmacy premises. Detailed discussion of each attribute is beyond the remit of this document; however, important aspects include marketing, financial management, administration, meeting and exceeding client expectations, satisfying legal obligations and developing the business over time. In essence, all pharmacists who trade within the community setting "sell" their expertise with the intention of turning over a profitable business. Within recent years, there has been an everpressing need to drive forward service provision such that business models are optimised.

Consequently, target-based working patterns are becoming increasingly prominent within the community pharmacy setting in the UK and in 2010 McDonald reported that many pharmacists had expressed concern over the amount of pressure to perform MURs to reach targets, hence suggesting some MURs were being undertaken for their ease with very little patient benefit. $^{11}$ Currently, pharmacies can claim a NHS reimbursement of GBP28 for every MUR performed; with a maximum of 400 per pharmacy, per year. ${ }^{11}$ Likewise, pharmacies delivering the NMS will receive a fixed one-off implementation payment of GBP750; following this the funding structure will be comprised of target payments only. ${ }^{10}$ Recent figures suggest that in July 2011 a total of 213,776 MURs were performed within England, equating to a cost to the NHS of GBP5,985,719. ${ }^{10}$ If a pharmacy conducts the maximum number of MURs per annum the operator will generate an extra income of GBP11,200. ${ }^{10}$ Although the introduction of such schemes may appear financially advantageous, one could argue that pharmacists may provide services without the desire or necessity to do so. ${ }^{7}$

Naturally, controversy exists surrounding financial incentives for service implementation. In relation to this, Latif and coworkers highlighted the danger that rather than being seen as a trusted and independent source of advice, attempts by community pharmacists to offer MURs to patients may lead patients to question their motives and believe that quantity has become prioritised over quality. ${ }^{12}$ Conversely, in order to maintain a successful business profit must now be obtained via service provision as pharmacies acquire less money from prescription volume and indeed if services are conducted properly, they can be extremely beneficial to the patient. ${ }^{13}$ With the advent of additional services it is imperative that pharmacists have knowledge of successful business management. In terms of patient attitudes towards the expanding role of the community pharmacist, it is evident that members of the general public are in favour of the implementation of additional services and the development of a pharmacist's skill set. ${ }^{14}$

The foundation for pharmaceutical care provision within primary and secondary care settings hinges squarely on student engagement and completion of both the undergraduate Master of Pharmacy (MPharm) degree offered at Higher Education institutions throughout the UK and a period of accredited pre-registration training. The overarching aim of such preparation is to provide individuals with the necessary skill set to effectively operate a registered community pharmacy premises or work 
efficiently within a hospital setting. Regardless of the career pathway chosen, a pharmacist must exhibit a sound clinical understanding and maintain the function of a pharmacy business. Currently, pharmacy education within the UK is controlled by the General Pharmaceutical Council (GPhC), formed in 2010. A key function of this organisation is to set and maintain standards on undergraduate I post graduate training ${ }^{15}$; aspects for consideration include therapeutics and pharmacology. It is evident that topics directly related to business do not feature. Whilst the GPhC standards aim to ingrain sound clinical knowledge, transferable skills and the ability to learn / operate independently, it is crucial that pharmacy education remains relevant and prepare undergraduates for forthcoming practice.

To date, relatively few Schools of Pharmacy within the UK have incorporated business management into their undergraduate curriculum. Whilst studying at institutions such as The University of Reading and Aston University, students may learn skills necessary to manage a successful community pharmacy business. Naturally, the intention is to produce pharmacists educated in healthcare, management policy and financial strategies to thus excel as future leaders within the field of pharmacy. ${ }^{16}$

Professional pharmacy organisations have underscored the need for management related skills to be taught to pharmacy students so that graduates are able to work effectively within the profession. For example, in 2011 Moultry demonstrated that students who had developed a business plan as part of their university course found that it enabled them to apply the management skills and theory that they had learnt about in class to their job role. ${ }^{2}$ The inclusion of entrepreneurship as well as a business element could also change undergraduate perceptions about the potential benefits and opportunities for success within an independent pharmacy environment. ${ }^{17,18}$

Due to the notable changes in the UK community pharmacy sector within recent years, we suggest that it is now timely to consider the delivery of a business related material within the MPharm undergraduate degree. Consequently, this study aims to gauge the opinions of UK registered pharmacists along with pharmacy undergraduates and academic staff at Liverpool John Moores University (LJMU) regarding the inclusion of business within the MPharm degree along with potential mechanisms for delivery.

\section{METHODS}

\section{Questionnaire Preparation and Ethical Approval}

Prior to the execution of this study, a thorough literature review was conducted in order to identify current opinion regarding the delivery of material relating to pharmacy business management within the academic / healthcare sector. Upon close inspection of the literature, it was clear that important themes for consideration included modern day pharmacy practice and the association between service provision and profitability, the way in which a business management module would be delivered to an undergraduate cohort, fundamental aspects required within a business management module and the personnel necessary to effectively deliver the taught material. To this end, typical questions for study participants included:

- To what extent do you believe business impacts upon the role of a pharmacist?

- Studying business at university would have aided career progression. [Pharmacist group]

- Studying business at university will aid career progression. [Student group]

- Which of the following personnel would be most suitable to deliver a business module?

- What business skills would be most valuable for life as a community pharmacist?

The questionnaire was prepared using a range of Likert statements based upon the recurrent themes. For instance, the Likert scales involved: 'To a great extent', 'To a moderate extent', 'To some extent', 'To a small extent' and 'To no extent'. In addition, opportunity was given for respondents to offer their views in 'free-text' boxes to enable the reasoning of key trends noted within the data. In the case of each sample (i.e. pharmacists, students and staff) the questionnaire was modified only slightly to account for the differing situations of each group, such modifications included the tense of the question and considered the role of the individual questioned, as exemplified above. Further to completion of the questionnaire and support materials (i.e. cover letter and participant information sheet) ethical approval was sought and subsequently obtained by the LJMU ethics committee.

\section{Questionnaire Distribution to Pharmacists}

During January 2012, a questionnaire pack was distributed to 600 community pharmacies located in the Merseyside and Cheshire regions of the UK. The pack consisted of a 30 item questionnaire, a covering letter, a participant information leaflet along with an A5 freepost response envelope for document return and confirmation of consent. At all times the information remained confidential. The questionnaires were coded for tracking purposes. In an attempt to boost the response rate, follow up calls were made to those pharmacies who did not respond after two weeks of receiving the questionnaire; if necessary, the questionnaire completed over the telephone or another questionnaire pack dispatched if requested.

\section{Questionnaire Distribution to MPharm Undergraduates}

All undergraduate students enrolled on the MPharm degree programme at LJMU were eligible to participate with this study. The student-based questionnaire was distributed along with cover letter and participant information leaflet to individuals currently registered on the MPharm degree at LJMU School of Pharmacy over a five week period in early 2012. The students were invited to complete the survey prior to lecture initiation. The population 
consisted of 183 first year students, 170 second year students, 183 third year students and 169 fourth year students (i.e. 705 students in total). Engagement with the questionnaire was both voluntary and anonymous. Upon completion and return of the questionnaire, consent to include the data provided was implied.

\section{Questionnaire Distribution to Academic Staff}

In a similar fashion, a questionnaire pack was prepared and distributed to 44 academic staff involved with various aspects of teaching Pharmacy at LJMU. The packs were distributed at the appropriate internal post boxes and included clear instructions for completion and return. The questionnaires were coded to provide scope to remind those who had not already replied to do so, in order to increase the response rate. Once again all data was treated confidentially.

\section{Statistical Analysis}

The data were collated and entered into the Statistical Package for the Social Science (SPSS) v18 platform to allow for statistical analysis; data entry was validated by second inspection. Initial analysis included the use of descriptive tools in order to obtain simple frequencies and crosstabulations for the more basic type of question such as what year pharmacists believe a business module should be introduced into the MPharm curriculum. Non-parametric techniques were employed in the data analysis as these do not require a normal distribution in the identification of underlying trends. Here, cross referencing between demographic questions and opinions (i.e. those enquiries containing Likert scales) included the Mann-Whitney test along with the Kruskal-Wallis test and the $p$ values were then recorded; where a $p$ value of less than or equal to 0.05 is believed to be of statistical significance.

\section{RESULTS}

\section{Pharmacist Demographics}

In terms of the pharmacist cohort, 271 completed questionnaires were received, providing a response rate of $45 \%$. Just over half of the participants were female $(51.9 \%)$. Overall, individuals were between 23 and 30 years old ( $36.7 \%), 31$ and 40 years old (26.2\%), 41 and 50 years old (16\%), 51 and 60 years of age $(16.7 \%)$ and over 61 years of age (4.4\%). Respondents were predominantly employed as pharmacist managers $(56.8 \%)$ followed by employee pharmacists (16.5\%), pharmacy owners (15.4\%) and locum / relief pharmacists (8.6\%). Pharmacy premises were mainly members of a national chain $(55.4 \%)$, followed by members of a small group (2-5 branches) (19.3\%), single

\begin{tabular}{|l|c|c|c|}
\hline \multicolumn{4}{|c|}{$\begin{array}{l}\text { Table 1. A summary of the questionnaire distribution and } \\
\text { return patterns for each sample within the study }\end{array}$} \\
\hline \multirow{2}{*}{ Cohort } & \multicolumn{2}{|c|}{ Questionnaires } & $\begin{array}{c}\text { Response } \\
\text { Rate (\%) }\end{array}$ \\
\cline { 2 - 3 } & Distributed & Returned & 45.0 \\
\hline Pharmacist & 600 & 271 & 92.0 \\
\hline $\begin{array}{l}\text { Undergraduate } \\
\text { Student }\end{array}$ & 441 & 406 & 54.5 \\
\hline Academic Staff & 44 & 24 & \\
\hline
\end{tabular}

independents (13\%) and local/regional chains $(10.8 \%)$. The most common locations of the pharmacies were high streets (29.1\%), town/city centres $(24.3 \%)$ and within doctors surgeries $(16.4 \%)$.

\section{Undergraduate Student Demographics}

With respect to pharmacy undergraduate students, a total of 441 students were present during questionnaire delivery with 406 students returning completed questionnaires; providing a response rate of $92 \%$. Here, $26.8 \%$ were 1 st year students, $27.1 \%$ were 2 nd year students, $19.5 \%$ were $3^{\text {rd }}$ year students and $26.6 \%$ were $4^{\text {th }}$ year students. Across all years there were a higher percentage of females, with an overall male to female student ratio of $42.3 \%$ to $57.7 \%$, respectively. With regards to career aspirations the majority of students (58.7\%) declared a desire to work in community pharmacy followed by hospital (32.4\%) and industry (5.7\%) with $3.2 \%$ of students choosing "other" (i.e. prisonbased pharmacy).

\section{Academic Staff Demographics}

At the outset 44 questionnaires were distributed to academic staff within the Pharmacy and Biomolecular Sciences Department at LJMU. A total of 24 individuals completed questionnaires were returned during the 5 week study period, providing a response rate of $54.5 \%$. The majority of respondents (62\%) held experience of the community pharmacy sector. Overall, 11 individuals indicated they possessed the MPharm qualification, with all having between 1-5 years experience working as a pharmacist prior to entering academia.

\section{Response Rate Summary}

The response rates from each cohort of the study are summarised in Table 1.

\section{Study Data}

The data obtained suggest that business acumen plays an increasing role in everyday responsibilities within modern community pharmacy premises (Table 2).

Overall, $76 \%$ of pharmacists would have chosen to study business at university if it were available. The data suggest that the availability of a business module in the MPharm degree would be of interest to undergraduates and would indeed be beneficial for future employment.

The pharmacist cohort believed that the availability of a business module with the pharmacy programme would have been extremely valuable as the material delivered would have aided career progression over time (Table 3).

\begin{tabular}{|c|c|}
\hline $\begin{array}{r}\text { Level } \\
\end{array}$ & Respondents (\%) \\
\hline To no extent & 0.7 \\
\hline To a small extent & 4.6 \\
\hline To some extent & 9.8 \\
\hline To a moderate extent & 28.2 \\
\hline To a great extent & 56.7 \\
\hline
\end{tabular}


Davies MJ, Fleming H, Jones R, Menzie K, Smallwood C, Surendar S. The inclusion of a business management module within the master of pharmacy degree: a route to asset enrichment? Pharmacy Practice 2013 AprJun;11(2):109-117.

\begin{tabular}{|l|c|}
\hline \multicolumn{2}{|l|}{$\begin{array}{l}\text { Table 3. Studying business at university would have } \\
\text { aided career progression }(\mathrm{n}=271)\end{array}$} \\
\hline \multicolumn{1}{|c|}{ Level } & Respondents (\%) \\
\hline Strongly agree & 18.2 \\
\hline Agree & 43.2 \\
\hline $\begin{array}{l}\text { Neither agree or } \\
\text { disagree }\end{array}$ & 25.7 \\
\hline Disagree & 10.9 \\
\hline Strongly disagree & 2.0 \\
\hline
\end{tabular}

It was evident that more than half of those surveyed $(61.4 \%)$ agreed with this sentiment, which naturally offers support for the introduction of a business module within the MPharm degree.

The pharmacist cohort indicated that the preferred positioning for a business module would be the $3^{\text {rd }}$ and $4^{\text {th }}$ year of study: $40 \%$ and $74.1 \%$, respectively. Furthermore, pharmacists suggested that if business material were to be incorporated it should feature as an elective (45.9\%) or a compulsory module (37.4\%). Workshops, lectures and community pharmacy visits were favoured choices for delivery with $75.5 \%, 65.9 \%$ and $54.3 \%$ of pharmacists supporting this, respectively. Furthermore, pharmacists were asked to consider the most appropriate type of professional to deliver a business management module to pharmacy undergraduates; for instance, business owners, accountants, business lecturers, pharmacy lecturers and teaching practitioners (Table 4).

Of those surveyed, business owners, business lecturers and teaching practitioners were considered best placed to deliver taught material to undergraduate students. Business owners could be considered as the most appropriate to teach the material, having acquired the required expertise and knowledge with time.

To determine the most appropriate skill set for delivery within a business module, pharmacists were asked to rank the following in order of importance to them: marketing skills, financial skills,

\begin{tabular}{|l|c|}
\hline \multicolumn{2}{|l|}{$\begin{array}{l}\text { Table 4. Community pharmacists' opinions regarding } \\
\text { appropriate personnel to teach business to } \\
\text { undergraduates }(\mathrm{n}=271)\end{array}$} \\
\hline \multicolumn{1}{|c|}{ Personnel Type } & Respondents (\%) \\
\hline Other & 5.6 \\
\hline Business owners & 65.1 \\
\hline Accountants & 14.6 \\
\hline Business lecturers & 53.8 \\
\hline Pharmacy lecturers & 25.2 \\
\hline Teaching practitioners & 60.1 \\
\hline
\end{tabular}

and management skills, knowledge of business models, pharmacy regulations, leadership and interpersonal skills (Figure 1).

The data suggest that management skills, pharmacy regulations, leadership skills and interpersonal skills are the most important aspects of business practice and would therefore be worthy of consideration in a business related module within the MPharm programme.

All students were asked to consider whether they would study business as part of their MPharm degree. Overall, a total of $64.3 \%$ confirmed that they would be interested, with $19 \%$ stating they would not and $16.7 \%$ being unsure. Of those interested students, $77 \%$ agreed that the completion of a business module would aid career progression; reflecting pharmacist opinion. Those students who thought a business module would aid career progression were statistically more likely to engage $(P=0.001)$.

A total of $92.8 \%$ of students believed business skills will have an impact upon their future role. Those students wishing to enter into community pharmacy were more likely to believe that business skills would impact on their future roles to a larger extent $(P=0.001)$. The bulk of students supported the point that business was important for inclusion within the MPharm degree.

Students were asked to consider into which year of the degree a business module should be

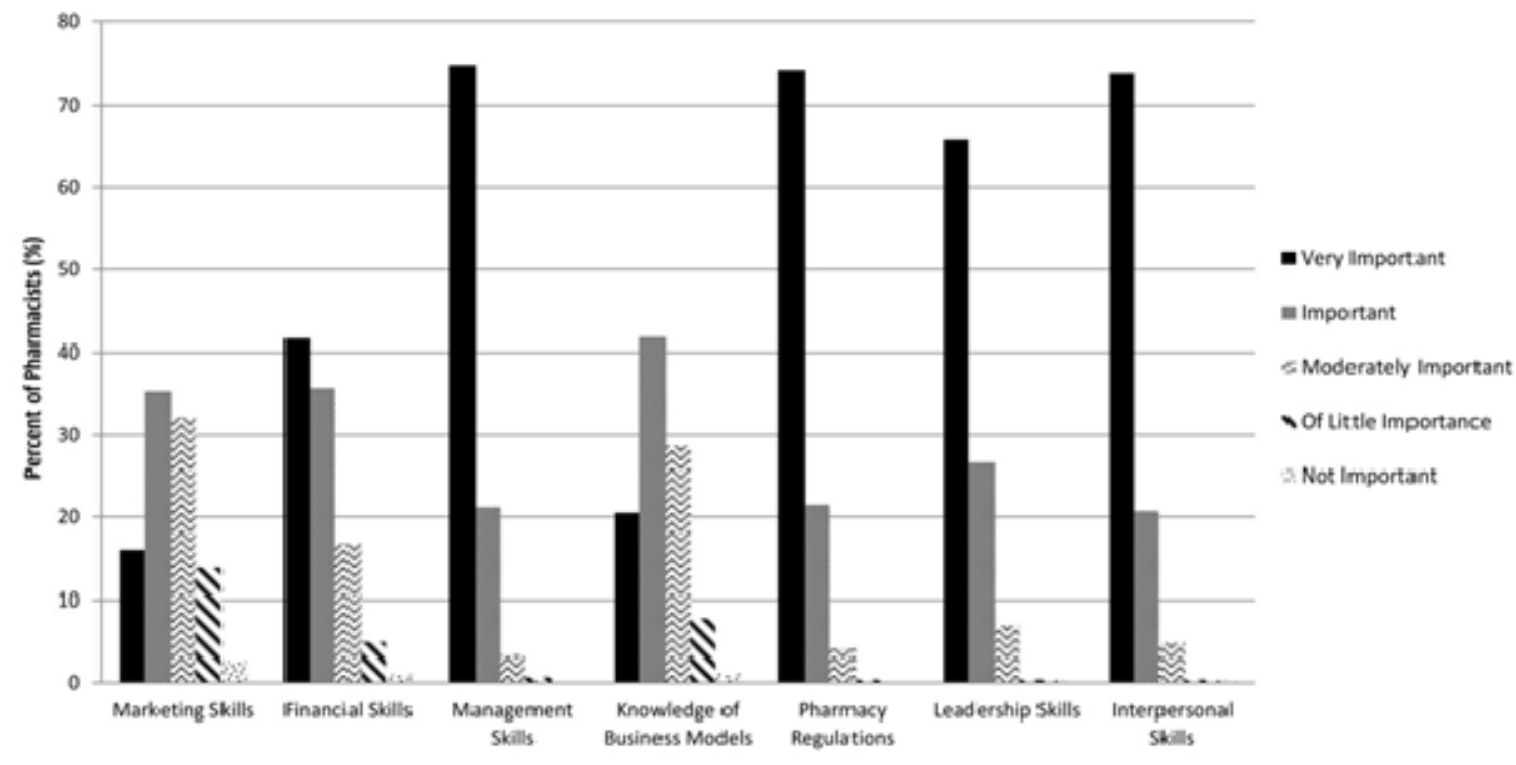

Figure 1. The value of key business skills for pharmacists in the current working environment $(n=271)$ 
incorporated. Here, the $3^{\text {rd }}$ and $4^{\text {th }}$ year of the degree course predominated with $44.7 \%$ and $59.8 \%$ opting for these years, respectively. This may be ascribed to the fact that the final two years of the degree would be closer to practice:

"Since these students will soon graduate they should focus more on the actual ability to run a pharmacy." 1st year pharmacy student

"At this stage students are focussed on their career and are very close to reaching the working environment." 2nd year pharmacy student

"Most important two years and closest to actually becoming a pharmacist and therefore a manager with business in mind." $3^{\text {rd }}$ year pharmacy student

"Able to learn skills and be able to remember and incorporate them into pre-registration training with the skills fresh in the mind." $4^{\text {th }}$ year pharmacy student

The majority of students (46.3\%) agreed that a business element should be incorporated into the degree as an elective module, whilst $24.6 \%$ of students thought it should be compulsory module and $23.6 \%$ thought it should be incorporated into a pre-existing module (i.e. Pharmacy Practice). Notwithstanding module placement, it would appear that the student cohort was generally in favour of a business module.

The most popular teaching methods were workshops (65.8\%) and lectures (62.6\%). A total of $37.4 \%$ of students suggested the provision of community pharmacy visits, thus indicating a desire for practical experience to underpin theoretical aspects. With regards to who should teach the module, popular choices included business lecturers (64\%), business owners (52.8\%), pharmacy lecturers (43\%) and teaching practitioners (41.5\%). The response to this question was variable, indicative of the fact that students would prefer input from a range of individuals.

The most popular teaching methods were workshops (65.8\%) and lectures (62.6\%). A total of $37.4 \%$ of students suggested the provision of community pharmacy visits, thus indicating a desire for practical experience to underpin theoretical aspects. With regards to who should teach the module, popular choices included business lecturers (64\%), business owners (52.8\%), pharmacy lecturers (43\%) and teaching practitioners (41.5\%). The response to this question was variable, indicative of the fact that students would prefer input from a range of individuals.

The MPharm undergraduate students were also tasked with rating elements of business practice on the basis of importance to them. Here, the cohort deemed pharmacy regulations as the most important aspect closely followed by management (i.e. marketing, financial management, stock procurement / supply and additional activities to ensure profitability), interpersonal and leadership skills. The trend in the data links well with responses obtained from the pharmacist cohort.
Interestingly, those students who wished to enter community pharmacy were more likely to rate marketing skills and knowledge of business models with greater importance $(P=0.001)$.

The majority of staff (79\%) agreed that business skills are becoming increasingly important and worthy of consideration. Academic staff were asked to consider if they would like to teach elements of business practice if included in the degree. UK registered academic pharmacists demonstrated greater interest in delivering a business module than academic staff members with expertise in other fields, with a proportion (36.3\%) showing interest. Academic pharmacists were more likely to feel qualified to teach on a business module than nonpharmacist staff. However, responses obtained from the academic pharmacists were not overwhelmingly positive (i.e. participants did not "strongly agree" with the question).

The final year of the MPharm degree was considered to be the most suitable point to deliver business related material. A clear majority $(79 \%)$ indicated an elective module in the $3^{\text {rd }}$ year $(29 \%)$ or $4^{\text {th }}$ year $(67 \%)$, worth 12 credits was the ideal way to deliver such a business module. The result may be rationalised due to the students at this point in the course holding a better understanding of pharmacy practice and the early stages of the degree are dedicated to acquiring fundamental scientific and practical knowledge.

In terms of personnel for module delivery, there was broadly equal favour towards teaching practitioners, business lecturers and business owners. Only one person indicated that accountants would be a suitable choice, this was unsurprising as an accountants job has a primarily financial focus and financial skills were not one of the skills staff prioritised. The highest rated discrete business skills were management, leadership, and interpersonal skills as well as knowledge of pharmacy law and legislature; reflecting the opinion from other groups.

\section{DISCUSSION}

Over the course of recent years the practice of community pharmacy has evolved considerably. Pharmacists currently play a much more active role in public health. With the introduction of the New Pharmacy Contract in 2005, changes in traditional pharmacy business models have taken place and one could argue that clinical knowledge is no longer sufficient to fully support activities within the community setting. Indeed, business acumen appears to be ever more important.

The MPharm degree aims to impart pharmaceutically relevant knowledge such that the individual may function effectively as a healthcare professional. Therefore, we argue that it would be prudent to implement a business management module within the MPharm degree as standard to ensure graduates are trained appropriately for current practice. This is so as the majority of newly qualified community pharmacists inherently manage a practice at the beginning of their career and often progress rapidly to become pharmacy managers 
post qualification, with some deciding to establish their own businesses. Typically, many individuals working within multiple chain pharmacies in developed countries (i.e. the UK and USA) often become pharmacy managers or area managers after just two years of practice. ${ }^{19,20}$ In addition, pharmacy graduates frequently advance to higher positions such as district or regional managers of chains within five to ten years of qualification. ${ }^{19,20}$ Naturally, those pharmacists that are capable of successful pharmacy business management (i.e. ensuring effective function and profitability) are more likely to be fast tracked to more senior, leadership roles. ${ }^{20}$ As a consequence, it would appear advantageous for newly qualified pharmacists to hold an understanding of business practice.

The three groups consulted within this study demonstrated support for the inclusion of business within the MPharm degree as they believe commerce is becoming a larger part of a pharmacist's everyday role. ${ }^{21}$ The majority of individuals suggested the $3^{\text {rd }}$ and $4^{\text {th }}$ years of the MPharm programme were most appropriate for the dissemination of business related material. The placement of the module at this stage in the degree may be rationalised by considering student development over time and related preparation for practice. At the early stages of the MPharm degree students are typically exposed to the more fundamental aspects of the profession with an ongoing emphasis given to clinical knowledge and the execution of practice-based models. It is during the latter stages of the degree that undergraduates are exposed to the wider issues of pharmacy practice and therefore at this point a business related module would be well-positioned to underpin understanding for future practice.

A number within the pharmacist grouping suggested business should be compulsory for study because commercial skills are essential for modern day community practice and it could well be argued that such skills support the activities of pharmacists within the hospital setting (i.e. understanding National Health Service budgets). ${ }^{22}$ Conversely, the majority of students believed that a business module should be delivered as an elective unit; thus presenting a mismatch in opinion. This discrepancy may be ascribed to the fact that the student body holds a limited appreciation of the significance business holds in modern day pharmacy practice. It would, of course, be interesting to probe 'student' opinion post qualification.

In planning module content and delivery one must take into account that learning styles between individuals vary greatly and a mix of educational techniques may offer a fully inclusive module. ${ }^{23,24}$ Moreover, the selection of appropriate staff with suitable skills will facilitate the execution of a successful module.

It is well-documented that practical experience is one of the most effective modes of learning within the field of pharmacy ${ }^{25-27}$ and the majority of students surveyed would prefer a business module to be taught via active workshops and lectures.
These approaches are useful vehicles to teach business fundamentals and subsequent community pharmacy visits could be arranged to enable practical experience and consolidate key learning objectives. In 2011 Guile and coworkers suggested that students often find it difficult to transfer theoretical knowledge and apply it to practical situations. ${ }^{28}$ Therefore, workshops and problem based learning (PBL) may assist students to experience scenarios they may encounter in the future, as per the post-graduate Medway Certificate for qualified community pharmacists. ${ }^{29}$

The data indicate business lecturers, owners and teaching practitioners would be suitably placed to deliver taught material. Business lecturers were viewed as important assets as they may provide students with essential business models that can be supplemented by individuals who operate profitable pharmacies. Previously, Moultry et al demonstrated that the involvement of business owners enhanced student learning. Here, a key attribute was the ability to develop business plans in collaboration with the owners. ${ }^{2}$ Additionally, pharmacy business owners can provide examples of relevant financial and managerial scenarios. ${ }^{21,26}$ Furthermore, teaching practitioners are a logical choice for inclusion within the staffing profile due to the experience of training individuals and spending time immersed in community pharmacy. Teacher practitioners may deliver business related aspects of pharmacy and underscore how the information links with patient care. Senft et al suggest that students benefit from material delivery via pharmacist managers, accountants and business consultants. ${ }^{25}$ It would therefore seem appropriate to employ individuals with a range of expertise in the delivery of a pharmacy business module.

With respect to the components of a business module, pharmacy regulations, management skills, interpersonal skills and leadership skills appear important. The tendency to rate skills associated with personnel management and ability to work with others more highly than those associated with profit may relate to a humanistic focus of the MPharm degree. $^{30}$ The effective management of staff within the workplace can be a daunting prospect for newly qualified pharmacists. The delivery of a range of business related skill sets may allow for the undergraduate to develop competency in managing people effectively, thus offering opportunity to run a profitable pharmacy business at the start of their career.

This very point is reflected in the study conducted by Granko et al in 2011, where the biggest challenge noted when recruiting pharmacists was their general lack of leadership skills and management experience. ${ }^{31}$

The World Health Organisation (WHO) suggests seven key roles that a pharmacist should fulfil during daily practice and according to their Good Pharmacy Education Practice policy and proposes all should be incorporated within their education; these include caregiver, decision-maker, communicator, manager, life-long learner, teacher and leader. ${ }^{32}$ Many of the current dual pharmacy 
and business degrees in the USA consider such elements with the curricula. ${ }^{2,22,25}$ To date, it is evident that there is a lack of leadership skills and pharmacy management skills amongst UK pharmacy graduates and pharmacists. ${ }^{31,33}$ Shortcomings in pharmacy education may be tackled by reference to The Royal Pharmaceutical Society Leadership Competency Framework for Pharmacy Professionals ${ }^{34}$, which highlights the need for leadership throughout the healthcare system in order to provide excellence in quality of care to patients. ${ }^{34}$ With the WHO indicating that pharmacists should hold managerial skills, perhaps it is now time to fully consider the implementation of Good Pharmacy Education Practice standards and hence enrich the asset that is the MPharm degree.

\section{CONCLUSIONS}

Pharmacists demonstrated a clear desire for the inclusion of a business module within the MPharm degree as a result of changes in the contractual framework and the increase in workplace targets I pressures. With the majority of students stating that they would study a business module if it were included within the degree course and that it would aid career progression there is obvious demand. The academic staff surveyed were not strictly opposed to the delivery of a business module within the MPharm degree but business topics did not hold the same priority as other subjects.

Perhaps a suitable approach at the outset would be to provide undergraduate students with the option of studying pharmacy business management and monitor progress over time. Should the taught material be well-received and deemed essential for study then a compulsory unit could be introduced to provide key information such that all students may readily transfer the knowledge into the pharmacy profession post qualification.

\section{ACKNOWLEDGEMENTS}

The authors would like to thank Liverpool John Moores for funding this research effort.

The authors would like to express their gratitude to all participants who took part in this study. Our special thanks go to Dr Phil Rowe for support during statistical analysis.

\section{CONFLICT OF INTEREST}

As far as the corresponding author is aware, no conflict of interest exists with this work.

\section{References}

1. Wongwiwatthananukit S, Popowich NG. Applying the ARCS model of motivational design to pharmaceutical education. Am J Pharm Educ. 2000;64:188-196.

2. Moultry A. A mass merchandiser's role in enhancing pharmacy students' business plan development skills for medication therapy management services. Am J Pharm Educ. 2011;75(7):133. doi: 10.5688/ajpe757133.

3. Pollock AM, Richardson E. Community pharmacy: moving from dispensing to diagnosis and treatment. BMJ. 2010;340:c2298. doi: 10.1136/bmj.c2298.

4. Jesson JK, Langley CA, Wilson KA, Hatfield K. Science or practice? UK undergraduate experiences and attitudes to the MPharm degree. Pharm World Sci. 2006;28(5):278-283.

5. National Audit Office, NHS Pay Modernisation: New contracts for general practice services in England executive summary. London: The stationary office 28/02/2008. Available online at: http://www.nao.org.uk/publications/0708/new_contracts_for_general_prac.aspx (Accessed 23/10/2011).

6. Pharmaceutical Services Negotiating Committee. The new NHS Community Pharmacy service - a summary of the structure. December 2004. Available online at: http://www.psnc.org.uk/data/files/PharmacyContract/pharmacy_contract_summary_dec_2004.pdf (Accessed 23/10/2011).

7. Feletto E, Wilson LK, Roberts AS, Benrimoj SI. Flexibility in community pharmacy: a qualitative study of business models and cognitive services. Pharm World Sci. 2010;32(2):130-138. doi: 10.1007/s11096-009-9355-3.

8. Department of Health. (2008). Pharmacy in England: Building on strengths- delivering the future. Available on line at : http://www.dh.gov.uk/en/Publicationsandstatistics/Publications/PublicationsPolicyAndGuidance/DH_083815 (Accessed 23/2/2012).

9. Bassey R. The business of pharmacy. PJ Online 2011. Available on line at: http://www.pjonline.com/blog_entry/the_business_of_pharmacy (Accessed 26/10/2011).

10. Pharmaceutical Services Negotiating Committee. Advanced Services Funding. 2011. Available on line at: http://www.psnc.org.uk/pages/advanced_services_fundinghtml.html (Accessed 4/3/2012).

11. McDonald R, Cheraghi-Sohi S, Sanders C, Ashcroft D. Professional status in a changing world: The case of medicines use reviews in English community pharmacy. Soc Sci Med. 2010;71(3):451-458. doi: 10.1016/j.socscimed.2010.04.021.

12. Latif A, Boardman H, Pollock K. The McDonaldisation of medicines use reviews. Int J Pharm Pract. 2009;4C(1):40.

13. Harding G, Wilcock $M$. Community pharmacists' perceptions of medicines use reviews and quality assurance by peer review. Pharm World Sci. 2010;32(3):381-385. doi: 10.1007/s11096-010-9381-1.

14. Eades CE, Ferguson JS, O'Carroll RE. Public health in community pharmacy: A systematic review of pharmacist and consumer views. BMC Public Health. 2011;11:582. doi: 10.1186/1471-2458-11-582.

15. General Pharmaceutical Council: Standards. Available on line at: http://www.pharmacyregulation.org/standards (Accessed 15/03/2012).

16. Richey-Smith C, Burgess J, Mehringer E. Affordable drug options: A survey of what colleges and schools of pharmacy are teaching. Currents in Pharmacy Teaching and Learning 2011;3(3):208-215. 
Davies MJ, Fleming H, Jones R, Menzie K, Smallwood C, Surendar S. The inclusion of a business management module within the master of pharmacy degree: a route to asset enrichment? Pharmacy Practice 2013 AprJun;11(2):109-117.

17. Hermansen-Kobulnicky CJ, Moss CL. Pharmacy Student Entrepreneurial Orientation: A Measure to Identify Potential Pharmacist Entrepreneurs. Am J Pharm Educ. 2004;68(5):113.

18. Frazier BJ, Niehm LS. Predicting the entrepreneurial intentions of non-business majors: A preliminary investigation. Proceedings of the USASBE/SBI Conference, Tucson, AZ. 2006: 14-17.

19. Desselle S, Zgarrick D. Pharmaceutical Care as a Management Movement. Pharmacy Management, Essentials For All Practice Settings. 2nd ed. United States of America: McGraw-Hill, 2009.

20. General Pharmaceutical Council. Standards for pharmacy owners, superintendent pharmacists and pharmacy professionals in positions of authority. 2010. Available from: http://www.pharmacypgd.co.uk/system/gphcstandards.pdf (Accessed 6/3/2012).

21. Bond C, Blenkinsopp A, Inch J, Celino G, Gray N. The Effect of the New Community Pharmacy Contract on the Community Pharmacy workforce. 2008. Available on line at:

http://www.pprt.org.uk/Documents/TrustNews/The_effect_of_the_new_community_pharmacy_contract_on_the_commu nity_pharmacy_workforce.pdf (Accessed 1/3/2012).

22. Chumney E, Ragucci K. Student Satisfaction and Academic Performance in a Dual PharmD/MBA Degree Program. Am J Pharm Educ. 2006;70(2):29.

23. Austin Z. Learning Styles of Pharmacists: Impact on Career Decisions, Practice Patterns and Teaching Model Preferences. Pharm Educ 2004;4(1):13-22.

24. Latif DA. Model for Teaching the Management Skills Component of Managerial Effectiveness to Pharmacy Students. Am J Pharm Educ 2002;66:377-380.

25. Senft SL, Thompson C, Blumenschein K. Dual Degree Programs at the University of Kentucky College of Pharmacy. Am J Pharm Educ 2008;72(1):12.

26. Calomo JM. Teaching Management in a Community Pharmacy. Am J Pharm Educ 2006;70(2):41.

27. Hyvärinen ML, Tanskanen $P$, Katajavuori N, Isotalus $P$. A method for teaching communication in pharmacy in authentic work situations. Communication Education 2010;59(2):124-145.

28. Guile D, Ahamed F. Modernising The Pharmacy Curriculum. 2011. Available from: http://www.llakes.org (Accessed 25 February 2012).

29. Medway School of Pharmacy. Postgraduate Certificate/Diploma in General Pharmacy Practice. 2011. Available from: http://www.msp.ac.uk/studying/postgraduate/cert-gen-pharm-pract/index.html (Accessed 25/2/2012).

30. Siracuse MV, Schondelmeyer SW, Hadsall RS, Schommer JC. Assessing Career Aspirations of Pharmacy Students. Am J Pharm Educ. 2004;68(3):75.

31. Granko RP, O'Neal BC, Fanikos J, Cohen BA, Cromes NV, Hicks DW, Thompson B, Poppe LB. The nonpharmacist business manager: Key qualifications and skills for success Am J Health Syst Pharm. 2011;68(19):1779-1782. doi: 10.2146/ajhp100675.

32. World Health Organisation. Developing Pharmacy Practice: a focus on patient care. Handbook 2006 edition. Available from: http://www.who.int/medicines/publications/WHO_PSM_PAR_2006.5.pdf (Accessed 14/3/2012).

33. Kerr RA, Beck DE, Doss J, Draugalis JR, Huang E, Irwin A, et al. Building a sustainable System of Leadership Development for Pharmacy: Report of the 2008-2009 Argus Commission. Am J Pharm Educ. 2009;73(8):S5.

34. Royal Pharmaceutical Society. Leadership Competency Framework for Pharmacy Professionals, 2010. Available from: http://www.rpharms.com/pressreleases-pdfs/1445---rps-Icf-document---final.pdf (Accessed 14/03/2012). 